\title{
Assessment of The role of Light in Welfare of Layers
}

\section{Hesham H. Mohammed*}

Veterinary Public Health Department, Faculty of Veterinary Medicine, Zagazig University, ElZeraa st. 114, 44511-Zagazig, Egypt.

\begin{abstract}
Due to the difference in spectral sensitivity between poultry and human, there was an importance to identify the optimal light environment for health, behavior, welfare, and production of layers. Overall birds have many types of retinal regional specializations, which have been interpreted with the respect to both ecology and behavior. Light is one part of a complex of the physical phenomenon called electromagnetic radiation, which is depending on its wavelength. Light consists of 3 different aspects; intensity, photoperiod, and spectral content color. Photoperiod manipulation is likely the most important aspect of light in poultry production. Lighting programs in laying hen farms are depending on photoperiod, whereas, one hour increase in daylength leads to increase in 4 egg numbers. Overall, the use of either an increasing or intermittent lighting program will improve the welfare over those birds raised on constant light photoperiods. Light source may have an effect on leg disorders, with the use of fluorescent bulbs causing a lower incidence of the problem as compared to incandescent bulbs. Furthermore, the light intensity plays important role in poultry welfare, where the decrease in light intensities may cause lower body weights by altering behavioral patterns and can also cause eye damage, increased mortality, and a result in physiological changes in the birds. The different light colors had significant differences in all behaviors, plumage scores, foot condition, and growth performance of layers due to presence of many types of retinal regional specializations. Thus, this article concludes that the source, spectra, intensity, and regime of light supplementation become major factors in modern poultry management

Keywords: Behavior, Light, Performance, Seeing, Walfare.
\end{abstract}

DOI:10.21608/svu.2019.23176

Received: September 23, 2018 Accepted: November 12, $2018 \quad$ Published: January 2, 2019 *Corresponding Author:Hesham H. Mohammed E-mail: heshamvet_hosny@yahoo.com

Citation: Mohammed HH, Assessment of The role of Light in Welfare of Layers. SVU-IJVS 2019, 2 (1): $36-50$.

Copyright: (C) Mohammed HH. This is an open access article distributed under the terms of the creative common attribution license, which permits unrestricted use, distribution and reproduction in any medium provided the original author and source are created.

Competing interest: The authors have declared that no competing interest exists. 


\section{Introduction}

Today, the poultry industry is believed to achieve perpetual and instant production of the best available sources of animal protein, and the increase towards poultry welfare on farms has led to studying the management (Mohammed and Rehan, 2018). The poultry differs from human in spectral sensitivity, which illustrates the importance to identify the optimal light environment for health, behavior, welfare, and production of chickens (Mohammed et al., 2018). They are sensitive to ultraviolet, blue, green and red on the light spectrum (Prescott and Wathes, 1999) through the retina and deep brain photoreceptors (Kuenzel et al., 2015).

One major prerequisite of higher life is light. Therefore, lighting is a major management factor in keeping of laying hens for egg production (Er et al., 2007). Lighting is described by photoperiod, light intensity and wavelength spectrum (Manser, 1996). Light intensity and emitted wavelengths depend on the used light sources. Interaction between photoperiod, light intensity and wavelength influence both behavior and performance of laying hen. Light is necessary for bird's vision influencing the visual acuity and color discrimination (Calvet et al., 2009). Moreover, the lighting system in chicken house must be designed and maintained in order to give a minimum illumination of 20 Lux, that enables thorough inspection and vision without difficultly (RSPCA, 2013). Lighting condition is the most important facet influence performance and welfare of animals. There is a need for suitable lighting condition to use best practice husbandry and management in Turkey (Case et al., 2010). The current knowledge on the effects of photoperiod and light intensity on the behavior and performance of laying hens is quite extended, whereas, information on the importance of wavelength alone and in combination with light intensity is still limited. Thus, the objectives of the project (light sources in layer houses) are to investigate the effects of different lighting sources on the behavior and performance of laying hens.

Light: (according to Mohammed, 2010)

Light is visible electromagnetic radiation. It has also been considered to be a combination of radiation and the response to it. Light is one part of a complex of physical the phenomena called electromagnetic radiation. The nature of phenomenon depending on its wavelength, beginning with cosmic rays, and lengthening through gamma-rays, X-rays, ultraviolet, visible light, infrared, microwaves, radar, television and radio. Whereas different wavelengths of light result in the perception of different color sensations, reception of radiation across the range is perceived as white light. Changes in wavelength of radiation can be achieved by using materials which absorb one wavelength and then give off another. For example, phosphors on the inside walls of low-pressure fluorescent lamps absorb the ultraviolet radiation generated by a mercury discharge and then emit visible light.

Aims of lighting programs for laying hens:

- Stimulate feed intake and growth

- Influence the timing of sexual maturity

- Maximize egg numbers

- Optimize egg weight

- Influence time of egg-laying

- Control undesirable behavior

Photoperiod and lighting programs: 
Photoperiod manipulation is likely the most important aspect of light in poultry production. Lighting programs in laying hen farms are depending on photoperiod, whereas, 1-h increase in daylength leads to increase in 4 egg numbers, 0.1 to $0.2 \mathrm{~g}$ in egg weight in both white and brown-egg hybrids (Lewis, 1996) and $1.3 \mathrm{~g}$ in feed intake, while the shell weight and shell thickness index $\left(\mathrm{mg} / \mathrm{cm}^{2}\right)$ decrease linearly with increasing photoperiod (Lewis et al., 1994). However, there are many disadvantages to constant lighting programs. Birds are less active, leg disorders are much more common and eye damage may occur (Manser, 1996). Metabolic problems are common (Buyse et al., 1996). Sleep of the birds is disturbed and physiological stress results (Gordon, 1994). Lighting programs are very important for broilers, but may even be more so for turkeys since their life span is longer (Nixey, 1994). The use of constant light in turkeys also results in a higher incidence of leg disorders and metabolic diseases (Classen et al., 1994). Er et al. (2007) mentioned that light duration was widely for improvement the reproductive performance of poultry. Mohammed et al. (2016) noted that the differences in photoperiods in layers associated with significantly differences in external and internal egg quality traits and its behavior. Overall, the use of either an increasing or intermittent lighting program will improve the welfare of either turkeys or broilers over those birds raised on constant light photoperiods.

The different light programs include continuous lighting, intermittent lighting, which includes Cornell (2L:4D: 8L:10D), Biomittent 16 (15 min L:45min D): 8, French symmetrical (3L:3D repeating) and Reading symmetrical (15 min L:45min D repeats), and Ephemeral program. (Mohammed, 2010)
Light sources:

Typically, incandescent bulbs were common in poultry houses. However, there has recently been a trend towards the use of fluorescent bulbs or high pressure sodium discharge lights because of their longer livability and lower costs (Mohammed et al., 2010). The type of light source used generally does not affect production parameters such as growth rates, feed efficiency or mortality in broilers (Lewis and Morris, 1998). The light source does not affect egg production, hatchability or growth rates in broiler breeders (Manser, 1996). Recent research has indicated that light source may have an effect on leg disorders, with the use of fluorescent bulbs causing a lower incidence of the problem as compared to incandescent bulbs (Lewis and Morris, 1998). As well, sexual maturity of laying hens, but not broiler breeders, may be delayed when incandescent bulbs are used in the barn.

Incandescent and fluorescent light have minimal UV content, which may represent a problem if exposure to UV light is important (Moinard and Sherwin, 1999).

When given the choice between fluorescent and incandescent light, turkeys choose the fluorescent. This may be because fluorescent light actually mimics daylight (Sherwin, 1999). The use of fluorescent light, which is more efficient and less expensive than incandescent, does not impair the welfare of turkeys. Two studies showed that the feather pecking was not affected by light sources (Denbow et al., 1990, Leighton et al., 1989). Sitting and feeding were observed more often than expected in incandescent light while nesting, preening, ground pecking, and drinking occurred more frequently than expected in high-pressure sodium light than incandescent and florecent light 
(Vandenberg and Widowski, 2000). The preening was higher in Fluorescent than incandescent light (Tina et al., 1992, Widowski et al., 1992) and also walking tends to be more evenly distributed between two light sources than the approximately $30 \%$ incandescent to $70 \%$ fluorescent light (Tina et al., 1992). According to North and Bell, (1993), the red light reduces cannibalism in laying hens due to the birds have no ability to see the blood of injured birds. An increase in wing stretching and both aggressive and non-aggressive pecking has been reported in chicken under red light compared with blue light (Prayitno et al., 1995). Prayitno et al. (1997a) found that the birds under red light spent more time in aggressive interactions, pecking at the floor, sleeping and wing stretching, but longer sitting and dozing under green or blue light, while, walking activity was greatest in white light and least in green light. According to Siopes (1984b) total egg production was significantly lower in fluorescent (67.9 egg/hen) than the incandescent treatment (75.2 egg/hen) but Siopes, (1984a) found that there were no significant difference between incandescent and fluorescent for hen-housed egg production, while total eggs laid per hen did not differ between blue and incandescent light (Pyrzak and Siopes, 1986a). No differences in total egg production and egg weight of hens kept under incandescent, high- pressure sodium vapor or fluorescent light (Felts et al., 1990). Hulet et al. (1992) reported that light sources had no significant effect on subsequent egg production, egg weight, shell quality, fertility or hatchability. Er et al. (2007) found that the egg weight in incandescent light was significantly greater than those in red light, while egg length in blue light was significantly shorter than other lights, and width was significantly shorter than those in incandescent. There were no statistical differences between incandescent, fluorescent and mercury vapor in the terms of other characteristics; breakage, shell thickness, albumen and yolk indexes, Haugh Unit and yolk color tone (Efil and Sarlca, 1998). Manser (1996) noted that light source does not effect on egg production and hatchability in broiler breeder. Egg weight was affected by light treatment, whereas, eggs lay under blue light were consistently larger than those laid under red light (Pyrzak et al. 1987). Pyrzak and Siopes (1986b) recorded that both the albumen and egg weight were higher in hens under red light than under green and blue light. There were no statistically significant differences in feed intake due to light sources (Lewis and Morris, 1998, Siopes, 1984a). Pyrzak and Siopes (1986a) revealed that the mean feed intake per day was also not significantly different between the treatment groups (202, 213, 210 and $213 \mathrm{~g} /$ day for the blue, green, red and incandescent treatments, respectively). Wabeck and Skoglund, (1974) found that the broilers raised under blue light (BL) gained significantly more weight than birds reared under red (RL) or white light (WL), whereas, feed conversion and mortality were not affected. According to Proudfoot and Hulan (1987), no significant differences in body weight or efficiency of roaster chickens reared under incandescent or green fluorescent lights. Both male and female hens grow more rapidly under blue light (Levenick and Leighton, 1988). Pyrzak et al. (1986) noted that an egglaying strain of chicken exposed to a blue light spectrum had significantly more abdominal fat at $20 \mathrm{WK}$ of age than those exposed to a red light spectrum and light emitted from incandescent bulbs and fluorescent tubes, while, layers exposed to the blue light weighed significantly less than those exposed to fluorescent tube. Sherwin et al., (1999) found that the amount of culling / death due to injurious 
pecking was significantly lower in incandescent and intermittent (incandescent and fluorescent) but not in fluorescent light. Mortality was higher in birds under fluorescent light (Leighton et al., 1989). Many studies showed that no significant difference in mortality rate in different light sources (Leighton et al., 1989, Lewis and Morris, 1996, Proudfoot and Hulan, 1987). The mortality rate was unaffected by light color or photoperiod for either male or female (Levenick and Leighton, 1988).

\section{Light Intensity:}

Light intensity plays important role in poultry welfare. Very low light intensities used in the broiler or the turkey production cycle may lower body weights by altering behavioral patterns causing active time to decrease, thereby resulting in the bird lying on the litter for longer times, possibly increasing the levels of skin blemishes due to ammonia contact (Jean-Loup et al., 2017). It can also cause eye damage, increased mortality, and a result in physiological changes in the birds (Buyse et al, 1996, Sherwin, 1998). Aggressiveness in birds is a problem, and research into the management procedures used to control this should continue, as the welfare of the birds can be reduced by the use of beak trimming in low light intensities (Sherwin, 1998). Excessively high light intensities may also be detrimental to birds. Reduced weight gains and increased aggression can result in broilers at light intensities of more than 150 Lux (Buyse et al, 1996). The only light source for chickens in environmental control houses is artificial. Thus, source, spectra, intensity and regime of light supplementation become major factors in modern broiler management (Andrews and Zimmerman, 1990). Kjaer and Vestergaard, (1999) showed that gentle pecks were approximately 20 times more frequent in 3 than 30 lux, whereas sever pecks were 2-3 times more frequent in 30 Lux of light source. Many studies showed that light intensity did not influence of cannibalism and feather pecking (Denbow et al., 1990, Hartini et al., 2002, Leighton et al., 1989, Tsuyoshi et al., 2006). While, Kjaer and Sorensen, (2002) found that light intensity had no effect on the rate of feather pecking in any of the genotypes, although about twice as much feather pecking was seen at 10 Lux compared to 3 Lux ISA breed but the difference not statistically significant. Reducing of light intensity plays important role in the control of cannibalism, reducing of injurious pecking and improves welfare (Classen et al., 1994, Hester et al., 1987, Hughes, 1982, Manser, 1996, Sherwin, 1998). Hartini et al., (2002) reported that the birds under the 5-Lux were calm, docile and non-aggressive but those reared under bright light were noisy. Light sources in strongly influence the incidence and severity of feather pecking and aggression with higher light intensity (Appleby et al., 1992, Braastaad 1986, Denbow et al., 1990, Vandenberg and Widowski, 2000). Light intensities of 10.8 and 86.1 Lux were equal in their effects on social behavior of both sexes (Gill and Leighton, 1984, Siopes, 1983). Bird activity increased as light intensity increased, which could have caused excess feed use and waste (Deaton et al., 1976). Mohammed et al., (2016) stated that it is better to use moderate light intensity to avoid abnormal behavior. Prayitno et al., (1997b) reported that an increase in intensity of red light increased the proportion of time spent (standing, walking, drinking, wing stretching, and aggression) and decreased dozing, sleeping, and pecking, while, an increase in blue light intensity only slightly increased wing stretching and aggression. Walking and total activity were higher 
under high light intensity (180 Lux) than low intensity (6 Lux), whereas feeding and drinking were not significantly affected by light intensity (Newberry et al., 1988). According to, Abdelkarim and Biellier, (1982) and Cavalchini et al., (1976) a linear increase in egg production as light intensity increased, while, Skoglung et al., (1975) found that egg production was the highest at locations with the lowest light intensity. No significant difference occurred in egg production under a light intensity (Hulet et al., 1992, Siopes, 1984a, Siopes, 1984b). Several studies showed that egg weight was not affected by light intensity (Cavalchini et al., 1976, Hulet et al., 1992, Isrea et al.1998, Siopes, 1984b, Siopes, 1992), while, Siopes, (1991) recorded that egg weight was significantly greater in the low intensity as compared with high intensity treatment. According to, Renema et al., (2001), by providing light intensities of 1, 5, 50 and 500 Lux, he reported linear decreases in egg weight (from 74.4 to $58.5 \mathrm{~g}$ ) and greater percentage of smaller eggs $(<56 \mathrm{~g})$. Hulet et al., (1992) reported that shell quality was also unaffected by light intensity. Yildiz et al., (2006) found that the negative correlation between light intensity and egg shell thickness, while, no differences in yolk weight, albumin index and egg shell weight. Two studies showed that there was no significant difference in feed intake under different light intensity (Charles, 1984 and Siopes, 1991). Reducing light intensity stimulated feed consumption as compared with high intensity (Downs et al., 2006). Isreal et al. (1998) found that feed consumption was significantly lower by $7 \%$ in $0.01 \mathrm{~W} / \mathrm{M}^{2}$ light intensity groups rather than $0.1 \mathrm{~W} / \mathrm{M}^{2}$ groups. Newberry et al., (1988) noted that feed consumption was not significantly affected by intensity at 3, 6 or 9 weeks of age, but in another experiment feed consumption for 6 weeks increased significantly with increasing light intensity. Siopes, (1984b) found that there were no statistically significant differences in feed intake due to light intensity during the entire 20-week test period, but at the end of the study, hens in lower light intensity consumed less feed than those in high intensity. Hartini et al., (2002) said that the birds reared under dim light consumed more feed than those reared under bright light. Deaton et al., (1987) found that light intensity had no significant effect on body weight and feed conversion (grams feed per gram body weight), while, Deaton et al., (1976) noted that the low light intensity (12.9 Lux) group of broilers had a significantly better feed conversion rate than those reared under a bright light (204.5 Lux). The mortality rate was not significantly affected by light intensity (Leighton et al. 1989, Newberry et al., 1986, Newberry et al., 1988). Kjaer and Vestergaard, (1999) found that high light intensity will increase the mortality rate specially from 16-46 week, while, Deaton et al., (1981) reported that higher mortality in chick brooder under 5 Lux than 75 Lux. Deaton et al., (1988) noted that light intensity had no significant effect on mortality at either 48 or 62 days of age for broilers of the same sex.

Wavelength:

Light wavelength via colored light may also be altered to reduce aggression in birds. Activity levels in turkeys are reduced when exposed to blue light versus white, green or red light (Manser, 1996). Broiler aggression is highest in red light and lowest in blue (Manser, 1996). Mohammed et al., (2010) found that light intensity may affect birds based on their sensitivity to wave length. Shabiha et al., (2013) found that blue and green light color had a shorter wavelength (480 NM, 
$520 \mathrm{NM}$, respectively) than red (700 NM) and yellow colors (580 NM).

\section{Light color:}

The source of light color can affect poultry performance (Jin et al., 2011). The green light activated growth rate, while the reddish orange light stimulated reproduction (Isreal et al., 2004). The green light can increase the growth of young birds, while the blue light stimulates the older ones (Classen et al., 2004). Mohammed et al., (2018) mentioned that the different light colors had significant differences in all behaviors, but with no significant differences observed in plumage scores, foot condition or growth performance among different light colors. Senaratna et al., (2011) reported that light colors had no effect on ingestive behavior, while Senaratna et al., (2012) stated that poultry was more active under red light.

\section{Physiology of seeing and metabolism in birds:}

Birds have relatively large eyes in comparison to humans. Light presents the chief exogenous regulator for the diurnal rhythm of the majority of animals (Sooyoung et al., 2011). Birds distinguish their conspecifics (Houser and HuberEicher, 2004), forage and explore their environment through the visual signals that demands light (Maddocks et al., 2001). Vision is essential for birds, but the metabolic demands of retinal processing, and also the costs of carrying large eyes, are likely to impose strong selective pressures to optimize performance (Martin and Osorio 2010). Like other vertebrates, birds have camera type eyes (Walls, 1942). Bird eyes are in general large, both in absolute and especially in relative terms compared to other vertebrates (Howland et al., 2004). Large eyes are heavy and therefore disadvantageous for flying.
Generally, larger eyes have longer focal lengths (Hughes, 1977), and thereby create larger images on the retina, which allows for higher spatial resolution.

Overall birds have many types of retinal regional specializations, which have been interpreted with respect to both ecology and behavior (Meyer, 1977). There is also a substantial energy cost associated with large eyes and the nervous tissue required to process the visual information (Moran et al., 2015). The fact that large eyes developed despite these costs is a testament to the importance of visual information for birds.

The both layers of the retina (outer segments and nuclear layer) have the photoreceptor cells that kick off visual information procedure through translating light into action potentials that pass through a variety of inter-neurons to the ganglion cells, whose axons make the optic nerve and additional to the visual cortex in the brain. Rods and cones are the two most important types of photoreceptors that diverge in anatomical configuration and their capability to absorb light of various wavelengths and illuminances (Osorio et al., 1999). Birds have six types of photoreceptors, one type of rod, one type of double cone, which does not exist in placental mammals, and four types of single cones (Hart, 2001a). As in many other vertebrates, the rods are likely not involved in colour vision but with their higher sensitivity provide achromatic vision in dim light (Kawamura and Tachibanaki, 2008). Colour vision is mediated by the four single cones (Osorio et al., 1999; Vorobyev and Osorio, 1998). Many vertebrates, except placental mammals, have double cones in their retinas (Walls, 1942) and in birds they are very numerous (Hart, 2001b). It has been proposed that achromatic vision in bright light is mediated by the double cones 
(Osorio and Vorobyev, 2005). The reasons are their broad spectral sensitivity, which has been found to be similar to the sensitivity of motion sensitive neurons (Campenhausen and Kirschfeld, 1998), their high abundance in the retina (Hart, 2001b) and their lack of participation in colour vision (Vorobyev and Osorio, 1998).

Avian eyes have an additional type of cone in the retina with peak sensitivity at about 415 NM (Govardovskii and Zueva, 1977, Hart et al., 1999) and these cones allow the detection of radiation below $400 \mathrm{NM}$ (Prescott and Wathes, 1999). Additionally, the lens and humors of the avian eye are optically clear between 320 and $400 \mathrm{NM}$ (Govardovskii and Zueva, 1977, Hart et al., 1999), and this means that poultry can see in the UV-A part of the ultraviolet range. According to Prescott and Wathes (1999), although birds have a fourth type of cone, peak avian sensitivity occurs in a part of the spectrum similar to that in humans (545 to $575 \mathrm{NM}$ ). Poultry see light differently from human, being more responsive to blue and red. As a consequence, hens perceive the light from incandescent lamps to be 10 to $20 \%$ brighter than that from fluorescent lamps, even when measurements on a light meter show the intensities to be the same.

Table 1. Perceived luminance by humans and domestic fowl at a distance of $1.5 \mathrm{~m}$ from light sources, with values calculated using spectral sensitivities, a lamp, a maximum spectral luminous efficacy of radiation for photopic vision of 683 lumen/w and a reflectance value of 0.2 :

\begin{tabular}{|c|c|c|c|c|}
\hline \multirow{2}{*}{ Light source } & \multirow{2}{*}{$\begin{array}{l}\text { Irradiance } \\
\left(\mathbf{W} / \mathbf{m}^{2}\right)\end{array}$} & \multicolumn{2}{|c|}{ Intensity perception } & \multirow{2}{*}{$\begin{array}{c}\text { Ratio of fowl to } \\
\text { human illuminance }\end{array}$} \\
\hline & & $\begin{array}{c}\text { Human } \\
\text { (Lux) }\end{array}$ & $\begin{array}{c}\text { Fowl } \\
\text { (gallilux) }\end{array}$ & \\
\hline $15 \mathrm{~W}$ incandescent lamp & $\mathbf{0 . 0 3}$ & 5.60 & 8.10 & 1.45 \\
\hline Warm white fluorescent tube & 0.28 & 120.80 & 147.20 & 1.22 \\
\hline Cool white fluorescent tube & 0.30 & 120.80 & 159.10 & 1.32 \\
\hline 70W sodium high pressure lamp & 0.52 & 254.40 & 227.30 & 1.09 \\
\hline 36W black light/ blue lamp & $\mathbf{0 . 2 8}$ & $\mathbf{0 . 7 0}$ & 31.10 & 41.86 \\
\hline 36W Blue fluorescent tube & 0.42 & 37.80 & 196.80 & 5.20 \\
\hline 36W Red fluorescent tube & $\mathbf{0 . 0 3}$ & 2.20 & 6.70 & 3.05 \\
\hline
\end{tabular}

$\mathrm{W}=$ the power output of lamp (W) in $5 \mathrm{NM}$ segments.

Poultry production represents a very large and diverse. There are many facets of production, and hence many areas that are potential concern for the welfare of the animals involved which reflected on the production. One of these areas include lighting programs, light is an important environmental factor that influences the behaviors, egg production, health of laying hens (Er et al., 2007). Manser, (1996) reported that light can be manipulated in four areas that may be helpful, including source, intensity, wavelength and photoperiod. Light permits birds to set up rhythmicity and harmonize several crucial functions, including body temperature and numerous metabolic steps that assist feeding and digestion. Furthermore, it promotes the secretion of some hormones that are implicated in the regulation of growth, maturation and reproduction (Olanrewaju et al., 2006). Light is 
absorbed by photopigments in retina to form inverted images that are converted into complex electrical signals for transmission to brain via the optic nerve. The light that reaches to brain, controls the secretion of gonadotrophin releasing hormone $(\mathrm{GnRH})$. This hormone is transported via the blood vessels to anterior pituitary gland where it stimulates the release of luteinizing hormone (LH) and follicle stimulating hormone (FSH). The amount and timing of gonadotrophin release influence the rate of sexual maturation. Many behavioral and biological responses are dependent upon retinal photoreception. In addition, light entering the eye stimulates the synthesis, release and metabolism of dopamine, which, suppresses the production of serotonin- $\mathrm{N}$-acetyltransferase, the main enzyme involved in the regulation of melatonin production in the retina during darkness. Buckland et al., (1976) reported that plasma corticoids were higher in broilers grow with continuous light compared with intermittent lighting programs, but Freeman et al., (1981) did not find a difference in plasma corticosterone between chicks grown with continuous or 12L:12D light schedules, although the chicks given continuous light were considered stressed because of adrenal hypertrophy and elevated plasma free fatty acid concentrations.

\section{References}

Abdelkarim MR, Biellier HV (1982). Effect of light intensity and photoperiod on chicken laying hens. Poultry Science, 61: 14031404.

Andrews DK, Zimmerman NG (1990). A comparison of energy efficient house lighting source and photoperiods. Poultry Science, 69: 1471-1479.
Appleby MC, Hughes BO, Elson HA (1992). Poultry production systems: Behaviour, Management and Welfare. CAB International: Wallingford, UK.

Braadstaad BO (1986). Rearing pullets in cages: high crowding has unfortunate effects. Poultry, 38-41.

Buckland RB, Bernon DE, Goldrosen A (1976). Effect of four lighting regimes on broiler performance, leg abnormalities and plasma corticoid levels. Poultry Science, 55: 10721076.

Buyse J, Simons P, Boshouwers F, Decuypere E (1996). Effect of intermittent lighting, light intensity and source of the performance and welfare of broilers. World's Poultry Science, 52: 121-130.

Calvet S, Van den Weghe H, Kosch R, Estellés F (2009). The influence of the lighting program on broiler activity and dust production. Poultry Science, 88: 2504-2511.

Campenhausen M, Kirschfeld K (1998). Spectral sensitivity of the accessory optic system of the pigeon. Journal of Comparative Physiology, 183: 16.

Case LA, Miller SP, Wood BJ (2010). Factors affecting breast meat yield in turkeys. World's Poultry Science, 66: 189-202.

Cavalchini LG, Pignatelli P, Sartore G (1976). Linfluenza della luca galline ovaiole. Rivista de Zootechnia Veterinaria, 2: 169-162.

Charles DR (1984). Amodel of egg production. Britsh Poultry Science, 25: 309-321.

Classen HL, Annet CB, Schwean-lardner KV, Gonda R, Derow D (2004). The effects of lighting programmes with twelve hours of darkness per day provided in one, six or twelvehour intervals on the productivity 
and health of broiler chickens. British Poultry Science, 45: S31S32.

Classen HL, Riddell C, Robinson FE, Shand PJ, McCurdy AR (1994). Effect of lighting treatment on the productivity, health, behaviour and sexual maturity of heavy male turkeys. British Poultry Science, 35: 215-225.

Deaton JW, Lott BD, Branton SL, Simmons JD (1988). Effectof differing light intensities on abdominal fat deposition in broilers. Poultry Science, 67: 12391242.

Deaton JW, Lott BD, Kubena LF, May JD (1976). Effect of varying light intensity on broiler performance. Poultry Science, 55: 515-519.

Deaton JW, Reece MW, McNaughton JL, Lott BD (1981). Effect of light intensity and low-level intermittent lighting on broiler performance during a high density, limited-area brooding period. Poultry Science, 60: 2385-2387.

Denbow DM, Leighton AT, Hulet RM (1990). Effect of light sourcesand intensity on growth performance and behaviour of femal turkeys. British Poultry Science, 31: 439445.

Downs KM, Lien RJ, Hess JB, Bilgili SF (2006). The effects of photoperiod length, light intensity, and feed energy on groth responses and meat yield of broilers. Applied Poultry Research, 15(3): 406-416.

Efil HA, Sarlca MB (1998). The effects of different light sources and lighting periods on layers production traits, feed consumption and egg quality in open poultry houses. Turkish Journal of Veterinary and Animal Sciences, 22(3): 197-204.
Er D, Wang Z, Cao J, Chen Y (2007). Effect of monochromatic light on the egg quality of laying hens. Applied Poultry Research, 16: 605612.

Felts JV, Leighton AT, Denbow DM, Hulet RM (1990). Influence of light sources on growth and reproduction of large white turkeys. Poultry Science, 69: 576-583.

Freeman BM, Manning AC, Flack IH (1981). Photoperiod and ist effect on the responses of the immature fowl to stressors.Comparative Biochemstry Physiology, 68A: 411-416.

Gill DJ, Leighton AT (1984). Effects of light environment and population density on growth performance of male turkeys. Poultry Science, 63: 1314-1321.

Gordon SH (1994). Effects of daylength and increasing daylength programmes on broiler welfare and performance. World's Poultry Science, 50: 269-282.

Govardovskii VI, Zueva LV (1977). Visual pigments of chicken and pigeon. Vision Research, 17: 537-543.

Hart NS (2001a). The visual ecology of avian photoreceptors. Progr. Retinal Eye Research, 20: 675-703.

Hart NS (2001b). Variations in cone photoreceptor abundance and the visual ecology of birds. Journal of Comparative Physiology, 187: 685697.

Hart NS, Partridge JC, Cuthill IC (1999). Visual pigments, cone oil droplets, ocular media and predicted spectral sensitivity in the domestic turkey (Meleagris gallopavo). Vision Research, 39(20): 321-328.

Hartini S, Choct M, Hinch G, Kocher A, Nolan J (2002). Effects of light intensity during rearing and beak trimming and dietary fiber sources 
on mortality, egg production and performance of ISA brown laying hens. Applied poultry research, 11: 104-110.

Hester PY, Sutton AL, Elkin RG (1987). Effect of light intensity, litter source and litter management on the incidence of leg abnormalities and performance of male turkey. Poultry Science, 66: 666-675.

Houser J, Huber-Eicher B (2004). Do domestic hens discriminate between familiar and unfamiliar conspecifics in the absence of visual cues? Applied Animal Behaviour Science, 85: 65-76.

Howland HC, Merola S, Basarab JR (2004). The allometry and scaling of the size of vertebrate eyes. Vision Research, 44: 2043-2065.

Huges BO (1982). Feather pecking and cannibalism in domistic fowls . in Bessei,W. (Ed.), Disturbed Behaviour in Farm Animal. Hohenheim Arbeiten, 121: 138146.

Hulet RM, Denbow DM, Leighton AT (1992). The effect of light source and intensity on turkey egg production. Poultry Science, 71: 1277-1282.

Iseal R, Zilberman E, Gvaryahu G (1998). New monochromatic light source for laying hens. Poultry Science, 77: 1695-1698.

Isreal R, Biran I, Chaiseha Y, Yahav S, Rosenstrauch A, Sklan D, Halevy $\mathrm{O}$ (2004). The effect of a green and blue monochromatic light combination on broiler growth and development. Poultry Science, 83: 842-845.

Isreal R, Issak B, Zehava U, Boaz R, Orna $H$ (1999). The effect of monochromatic light on broiler growth and development. Poultry Science ,78: 135-138.
Jean-Loup R, Katie C, Peter J, Greg M (2017). Light intensity of 5 or 20 lux on broiler behavior, welfare and productivity. Poultry Science, 96(4): 779-787.

Kawamura S, Tachibanaki S (2008). Rod and cone photoreceptors: Molecular basis of the difference in their physiology. Comparative Biochemical Physiology, 150: 369377.

Kjaer JB, Sorensen P (2002). Feather pecking and cannibalism in freerange laying hens as affected by genotype , dietary level of methionine + cystine, light intensity during rearing and age at first access to the range area. Applied Animal Behaviour Science, 76: 21-39.

Kjaer JB, Vestergaard KS (1999). Development of feather pecking in relation to light intensity. Applied Animal Behaviour Science, 62: 243-254.

Kuenzel WJ, Kang SW, Zhou ZJ (2015). Exploring avian deep-brain photoreceptors and their role in activating the neuroendocrine regulation of gonadal development. Poultry Science, 94: 786-798.

Leighton AT, Hulet RM, Denbow DM (1989). Effect of light sources and light intensity on growth performance and behaviour of male turkey. British Poultry Science, 30: 563-574.

Levenick CK, Leighton AT (1988). Effects of photoperiod and filtered light on growth, reproduction and mating behavior of turkeys.1. Growth performance of two lines of males and females. Poultry Science, 67: 1505-1513.

Lewis PD (1996). The domestic hen's response to photoperiodic influences, in: Proceedings $\mathrm{XX}$ 
World Poultry Congress, New Delhi, India. II: 737-745.

Lewis PD, Morris TR (1998). Responses of domestic poultry to various light sources. World Poultry Science, 54: 7-25.

Lewis PD, Morris TR (1999). Light intensity and performance of domestic pullets. World's Poultry Science, 55: 241-250.

Lewis PD, Perry GC, Morris TR (1994). Lighting and egg shell quality. World Poultry Science, 50: 288291.

Maaocks S, Church C, Cuthill I (2001). The efects of the light environment on prey choice by zebra finches. Journal of expermental biology, 204: 2509-2515.

Manser CE (1996). Effects of lighting on welfare of domestic poultry: a review . Animal Welfare, 5: 341360.

Martin GR, Osorio DC (2008). Vision in Birds. In The senses: A Comprehensive Reference (eds. Masland, R. H. and Albright, T. D.) Academic Press. San Diego. USA. pp. 25-52.

Meyer DB (1977). The Avian Eye and Its Adaptations. In: Handbook of Sensory Physiology. Vol. VII/5 (ed. F. Crescitelli), pp. 549-611.

Mohammed HH (2010). Cannibalism in laying hens. Ph.D. Thesis, Department of Veterinary Public Health, Faculty of Veterinary Medicine, Zagazig University, Egypt.

Mohammed HH (2016). Effect of different photoperiods on some maintenance behavior, external and internal egg quality traits of layers. Japanese Journal of veterinary science, 64(2): S139-142.

Mohammed HH, Grashorn MA, Bessei W (2010). The effects of lighting conditions on the behavior of laying hens. European Poultry Science, 74: 197-202.

Mohammed HH, Mohamed I, Al-Sadik S (2016). Effect of different light intensities on performance, welfare and behaviour of turkey poults. Journal of Advanced Veterinary and Animal Research, 3(1): 18-23.

Mohammed HH, Rehan I (2018). The titer of immunity and signs of welfare due to changes in group size in two strains of lohmann classic layers. International Journal of Veterinary Science, 1(1): 82-89.

Mohammed HH, Shereen E, Enas N (2018). Impact of different light color in behavior, welfare parameters and growth performance of Fayoumi broiler chickens strain. Journal of the hellenic veterinary medical society, 69(2): 951-958.

Moinard C, Sherwin CM (1999). Turkeys prefer fluorescent light with supplementary ultraviolet radiation. Applied Animal Behaviour Science, 64: 261-267.

Moran D, Softley R, Warrant EJ (2015). The energetic cost of vision and the evolution of eyeless Mexican cavefish. Science Advances, 1: e1500363-e1500363.

Newberry RC, Hunt JR, Gardiner EE (1986). Light intensity effects on performance, activity,leg disorders, and sudden death syndrome of roaster chickens. Poultry Science, 65: 2232-2238.

Newberry RC, Hunt JR, Gardiner PO (1988). Influence of light intensity on behaviour and performance of broiler chickens. Poultry Science, 67: 1020-1025.

Nixey C (1994). Lighting for the production and welfare of turkeys. 
World's Poultry Science, 50: 292294.

North MO, Bell DD (1993). Commercial chicken production manual. $4^{\text {th }} \mathrm{ed}$. AVI publishing Co., westport, CT.

Olanrewaju HA, Wongpichet S, Thaxton JP, Dozier WA, Branton SL (2006). Stress and acid-base balance in chickens. Poultry Science, 85: 1266-1274.

Osorio DC, Vorobyev M (2005). Photoreceptor spectral sensitivities in terrestrial animals: Adaptations for luminance and colour vision. Proceeding of Royal Society, 272: 1745-1752.

Osorio DC, Vorobyev M, Jones CD (1999). Colour vision of domestic chicks. Journal of Experimental Biology, 202: 2951-2959.

Prayitno DS, Philips CJ, Omed H (1997a). The effects of color of lighting on behavior and production of meat chickens. Poultry Science, 76: 452457.

Prayitno DS, Philips CJ, Omed HM, Piggins D (1995). The effect of colour of lighting on the performance and behaviour of broilers. British Poultry Science, 35: 173-175.

Prayitno DS, Philips CJ, Stokes DK (1997b). The effects of colors and intensity of light on behavior and leg disorders in broiler chickens. Poultry Science, 76: 1674-1681.

Prescott NB, Wathes CM (1999). Spectral sensitivity of the domestic fowel. British Poultry Science, 40: 332339.

Proudfoot FG, Hulan HW (1987). Agonistic behaviour, the development of the social hierarchy and stress in genetically divers floks of chickens. Behavioural Processes, 5: 339-354.
Pyrzak R, Siopes TD (1986a). Effect of light quality on egg production of caged turkey hens. Poultry Science, 66: 199-200.

Pyrzak R, Siopes TD (1986b). The effect of light color on egg quality of turkey hens in cages. Poultry Science, 65: 1262-1267.

Pyrzak R, Snapir N, Goodman G, Arnon E, Perek M (1986). The influence of light quality on initiation of egg laying by hens. Poultry Science, 65: 190-193.

Pyrzak R, Snapir N, Goodman G, Perek M (1987). The effect of light wavelength on the production and quality of eggs of the domestic hen. Theriogennology, 28: 947-960.

Renema RA, Robinson FE, Feddes JJ, Fasenko GM, Zuidhof MJ (2001). Effects of light intensity from photostimultion in four strains of commercial egg layers: 2. Egg production parameters. Poultry Science, 80: 1121-1131.

RSPCA (2013). RSPCA welfare standards for chickens, PP 10-11.

Senaratna D, Samarakone TS, Madusanka AP, Gunawardane WD (2011). Performance, behavior and welfare aspects of broilers as affected by different colors of artificial light. Tropical Agricultural Research, 14: $38-44$.

Senaratna D, Samarakone TS, Madusanka AP, Gunawardane WD (2012). Preference of broiler chicken for different light colors in relation to age, session of the day and behavior. Tropical Agricultural Research, 23: 193-203.

Shabiha S, Hassan R, Choe HS, Ryu KS (2013). Impact of different monochromatic LED light color and bird age on the behavioral output and fear response in ducks. 
Italian Journal Animal Science, 12: 573-579.

Sherwin CM (1998). Light intensity preferences of domestic male turkeys. Applied Animal Behaviour Science, 58: 121-130.

Sherwin CM (1999). Domestic turkeys are not averse to compact fluorescent lighting. Applied Animal Behaviour Science, 64: 47-55.

Sherwin CM, Lewis PD, Perry GC (1999). Effects of environmental enrichment, flourescent and intermittent lighting on injurious pecking amongst male turkey poults. British Poultry Science, 40: 592-598.

Siopes TD (1984a). The effect of fullspectrum flourescent lighting on reproductive traits of caged turkey hens. Poultry Science, 63: 11221128.

Siopes TD (1984b). The effect of high and low intensity cool-white fluorescent lighting on reproductive performance of turkey breeder hens. Poultry Science, 63: 920-926.

Siopes TD (1991). Light intensity effects on reproductive performance of turkey breeder hens. Poultry Science, 70: 2049-2054.

Siopes TD (1992). Effect of light intensity level during prelay light restriction on subsequent reproductive performance of turkey breeder hens. Poultry Science, 71: 939-944.

Siopes TD (2007). Lighting for summer egg production by turkeys:day length and light intensity. Poultry Science, 86: 2413-2419.

Siopes TD, Timmons MB, Baughman GR, Parkhurst CR (1983). The effect of light intensity on the growth performance of male turkeys. Poultry Science, 62: 2336-2342.

Skoglund WC, Palmer DH, Wabeck CJ, Verdaris JN (1975). Light intensity required for maximum egg production in hens. Poultry Science, 54: 1375-1377.

Sooyoung C, Gi S, Kyungjin K (2011). Circadian rhythm of adrenal glucocorticoid: Its regulation and clinical implications. Biochimica et Biophysica Acta, 1812(5): 581-591.

Tina M, Keeling L, Duncan IJ (1992). The preferences of hens for compact flourescent over incandescent lighting. Departement of Animal and poultery science, University of Guelph, Guelph, Ontario, Canada. Canadian Journal of Animal Science, 72: 203-211.

Tsuyoshi S, Yusuke E, Katsuji U, Toshio T (2006). Effects of light intensity and beak trimming on preventing aggression in laying hens. Animal Science, 77: 447-453.

Tullett SG, Macleod MG, Jewitt TR (1980). The effects of partial defeathering on energy metabolism in laying fowel. British Poultry Science, 21: 241-245.

Vandenberg C, Widowski TM (2000). Hens preferences for high- intensity High-Pressure Sodium or lowintensity incandescent lighting. Applied Poultry Research, 9: 172178.

Vorobyev M, Osorio DC (1998). Receptor noise as a determinant of colour thresholds. Proceeding of Royal Society, 265: 351-358.

Walls G (1942). The vertebrate eye and its adaptive radiation. Reprinted (2013) by: Martino Publishing. Mansfield Centre. Canada.

Webeck CJ, Skoglund WC (1974). Influence of radiant energy from florescent light source on growth, mortality and feed conversion of broilers. Poultry Science, 53: 20552059. 
Yildiz A; Lacin E; Hayirli A, Macit M (2006). Effects of cage location and tier level with respect to light intensity in semiconfined housing on egg production and quality during the late laying period. Applied Poultry Research, 15: 355361. 